\title{
5 How to become less excellent
}

\author{
Nick Butler and Sverre Spoelstra
}

\section{Introduction $^{1}$}

In 2014, Culumber et al. published an article in the international behavioural biology journal Ethology entitled 'Variation in melanism and female preference in proximate but ecologically distinct environments' (Retraction Watch 2014). This article would have passed unnoticed (at least by us) if it had not been for a peculiar anomaly. In place of a citation to a paper by a fellow biologist, the authors had forgotten to delete a question they had inserted for themselves: 'Should we cite the crappy Gabor paper here?' This slip (subsequently corrected by the journal) is revealing for the way it lifts the lid on processes of academic knowledge production that normally remain hidden from view. It shows that scholars are sometimes willing - or feel compelled - to cite academic articles that they evidently do not hold in high regard. It is unsurprising that the Culumber et al. paper went viral after being featured on the website Retraction Watch: scholars recognize in it the temptation to play the publication game even when it goes against their better knowledge.

Such game-playing extends beyond adding a reference to a 'crappy' paper here and there, and encompasses a range of research practices that are becoming increasingly prevalent in the contemporary university. Would it be an exaggeration to say that we target journals not because they publish interesting or worthwhile research, but because they are highly ranked; that we collaborate with esteemed colleagues not because we value their input, but because they increase our chances of getting published; and that we revise our papers not because we believe such changes are needed, but because we hope to appease reviewers and journal editors? Recent work suggests that this is no overstatement (Davis 2014; Macdonald 2014; Martin 2013).

This chapter examines forms of game-playing in the business school by focusing on the way that the regime of excellence - understood primarily in terms of journal rankings and research assessments - comes to modify academics' relationship to scholarship. Following Bristow (2012: 238), we aim to show how academics, when faced with 'the daily seduction of opportunities', may find themselves 'compromising just a little, and then a little bit more'. We do so by presenting a series of vignettes that illustrate how excellence is not simply 
imposed on academics from the outside, but is a set of relations they voluntarily maintain with themselves and others. In our earlier papers on the topic of excellence, we focused respectively on the suspension of subjectivity among academics and the reshaping of epistemic virtues within critical management studies (CMS) (Butler \& Spoelstra 2012; 2014). By contrast, this chapter offers some suggestions on how we might disrupt academic game-playing in the business school. This, we suggest, will allow us to become 'less excellent' - and hopefully also better scholars.

The chapter is structured as follows: We begin by reviewing the literature on the rise of excellence, focusing on the impact of journal rankings and research assessments on academic working lives. After describing the background to the chapter, we move on to our empirical material where we show how scholars willingly accede to the 'rules of the game' in academia and, in so doing, reconfigure the conditions of knowledge production in the business school. This provides an entry-point for a discussion on how to counteract the influence of journal lists and research audits on academic work.

\section{The rise of excellence}

In recent years, 'excellence' has emerged as a key discourse within the contemporary university (Readings 1996; Rolfe 2013). Originating in the private sector and the rise of New Public Management in the 1980s and 1990s (Deem et al. 2007), 'excellence' involves orientating academic knowledge production around metrics such as journal rankings, impact factors and league tables. To this extent, it is aligned with neoliberal 'audit culture' that seeks to measure and assess the products of academic labour as discrete units of value rather than as primarily scholarly contributions (Craig et al. 2014; Shore \& Wright 1999). What is important for the allocation of funding and resources within universities, in other words, is less the intrinsic merit of a piece of published work than its performance according to purely quantitative criteria (e.g. 1-star, 2-star, 3-star, 4-star). This is illustrated most clearly by the Research Excellence Framework (REF) in the UK, the Performance Based Research Fund (PBRF) in New Zealand and the Excellence in Research (ERA) in Australia. These trends indicate that 'excellence' is coming to serve as the new master-concept within higher education to the extent that it shapes the prerogatives of universities, departments, joumals and individual scholars.

The regime of excellence has not evaded analysis in the business school. Journal rankings in particular have come under scrutiny from management scholars, especially in relation to the Association of Business Schools Academic Journal Guide (commonly known as the 'ABS list'). While some defend journal rankings on the basis of transparency and accountability (Rowlinson et al. 2011; 2015), the dominant response has been highly critical of 'journal list fetishism' (Hussain 2015; Willmott 2011). On this view, the ABS list is said to be partial and exclusionary in its 'one size fits all' approach to evaluating the merits of scholarship, effectively marginalizing non-mainstream and heterodox approaches to 


\section{Nick Butler and Sverre Spoelstra}

management and organizations (Hussain 2011; Mingers \& Willmott 2013; Nkomo 2009; Northcott \& Linacre 2010). This highlights the performative nature of the ABS list: rather than neutrally measuring research quality post factum, it actively incentivizes academics to target highly ranked journals /are more orthodox and managerialist in orientation (Tourish \& Willmott 2015). Journal rankings thus serve to limit the scope of scholarly inquiry in the business school, which has led to calls for an outright 'moratorium on journal-ranking lists' (Tourish 2010).

In addition to its deleterious effects on scholarship, scholars have also drawn attention to the impact of excellence on the identity and subjectivity of management researchers. A few auto-ethnographic pieces have shown how individual academics come to fall under the spell of excellence, especially in the early stages of their careers (Prasad 2013; Cederström \& Hoedemaekers 2012). Malsch and Tessier (2015), for example, note how the institutional demand to publish in 'A' journals can compel junior researchers to adopt contradictory directions both intellectually and professionally, producing stress and anxiety as they navigate competing demands. Bristow (2012), meanwhile, points out that the shift from doctoral student to lecturer involves a sudden - and unwanted realignment of research prerogatives around a publish-or-perish mentality. Other scholars note that the subjective disposition of mid- to late-career researchers is also moulded in line with the diktats of excellence, often with little resistance (Butler \& Spoelstra 2014; Clarke et al. 2012; Knights \& Clarke 2014). It is important to recognize, however, that while excellence is to some extent imposed on academics extemally by research audits, university deans and promotion committees, it is also reproduced - implicitly or explicitly - by individuals through their own research practices. This leads Knights and Clarke (2014: 348) to suggest that management academics 'are not just victims but also perpetrators of the audit and accountability culture'.

This complicity is found most obviously in the metaphor of the 'publication game' (Townsend 2012). This underscores the way that academic knowledge production is coming to be viewed as a way of gaining personal and professional advantage, rather than first and foremost a means to contribute meaningfully to urgent social, political or organizational issues (Prasad 2013). For example, Macdonald and Kam $(2007 ; 2011)$ view impact factor manipulation by journal editors and strategies of self-citation by authors as types of academic 'gamesmanship' that distort the nature and purpose of scholarship. Similarly, Cederström and Hoedemaekers (2012: 231) note that the 'academic game' involves, paradoxically, both pleasure and pain: we lament its effects on scholarship, yet continue to (compulsively) produce more and more articles, deploying all the tricks of the trade in pursuit of 'excellence'. While some scholars suggest that it may be possible to 'win' the game of academia (McDaniel \& Childers 2011), there is an emerging awareness that we might all, ultimately, have much to lose in a university that is becoming progressively oriented around corporate principles of efficiency and competition, which have replaced more traditional modes of collegial engagement (Lucas 2006).

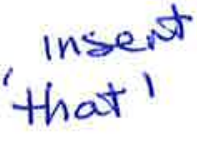


Some commentators have proposed various alternatives to excellence in the business school. Speaking from a US context, Ashforth (2005) puts the blame on the tenure track system that encourages young academics to pursue safe, unimaginative research that is likely to be published in the 'right' outlets; the solution, therefore, is to replace the tenure track system with regular performance reviews. Others call upon university departments to do away with the ABS list entirely, 'acknowledging the folly of the monstrous creation [and therefore] abandon its use' (Tourish \& Willmott 2015: 45). Some propose different measures for academic evaluation, such as impact factors and citation rates (Adler \& Harzing 2009; Alvesson \& Sandberg 2013), despite well-documented problems with such metrics (Fleck 2013; Macdonald \& Kam 2011). In terms of academic journals, Davis (2014: 199) recognizes that reorganizing peer review - for example, introducing a 'pass or fail' single-round review process - will have the effect of modifying incentive structures in the field.

While such proposals are valuable, they tend to emphasize system-level alternatives to excellence. However, it is important not to overlook the role that academics play, individually, in reproducing the logic of excellence in their everyday research practices. Bringing this to light - and proposing ways to disrupt academic game-playing - is the task of the remainder of the chapter.

\section{Background}

This chapter emerges from a broader research project on the politics of 'excellence' in the university-based business school (Butler \& Spoelstra 2012; 2014). At the heart of the project is a concern for the way in which the 'machinery of publishing' (Tienari 2012) impacts on the working lives and research practices of management and organizational scholars. The motivation for this study arose in part from the personal background of the authors. We both completed our doctoral research in an academic environment that encouraged critical thinking and sustained scholarly engagement, insulating us from the worst aspects of academic game-playing. Upon making the shift from doctoral research to our first lecturing positions, we increasingly found that we faced considerable institutional and peer pressure to align our research with the external demands of 'excellence'. Sometimes this pressure was exercised in the context of formal meetings with a director of research or other senior research staff in our respective departments. More commonly it was exerted in gentler ways, such as career advice from well-meaning professors to target certain journals rather than others (which usually aligned with the ABS ranking system) or conversations with friends and colleagues about our long-term 'publication strategies' (which rarely meant writing a scholarly monograph).

It soon became clear to us that the research environment in which we were now located was guided by a very different set of principles to the one in which we had conducted our Ph.D.s. Moreover, there was a dawning sense that our own research practices had gradually come to be shaped in unforeseen ways by the regime of excellence, and not always for the better. One of the 


\section{Nick Butler and Sverre Spoelstra}

authors certainly found himself trying - and failing - to write on research topics that left him uninspired for journals he never actually read, all in the name of building a portfolio of 'REF-able' publications. This certainly chimes with the experiences of other early-career researchers in the business school, who find themselves unexpectedly changed by the publish-or-perish mentality as they enter the profession (Bristow 2012; Prasad 2013). Our project was therefore prompted by the desire to find out how this has happened - to ourselves as much as others - and what might be done about it.

Towards this end, we conducted 31 in-depth semi-structured interviews with professors who are associated with the critical management community. We chose to interview exclusively professors because they can be considered as 'gatekeepers' to the field of which they are also a part. This is reflected in the fact that our respondents not only publish in the top-tier outlets but also influence the kind of research that is published in them by serving on various editorial boards. Such actors are therefore ideally placed to provide an insight into the way research is conducted in the business school today, especially in terms of institutional pressures and personal motivations for pursuing 'excellence'. At the time of our interviews, 21 of our respondents were based in the UK, five elsewhere in Europe, three in Australia and two in the USA. Twenty-five of our respondents were male and six were female, which is just below the percentage of female professors working in the UK according to the most recent statistics (22.4 per cent) (Higher Education Statistics Agency, 2014).

In this chapter, we use vignettes to explore personal 'short stories' about the process of research in more detail. While our empirical material may be shocking to some, we have ample examples of game-playing to draw on in our data - some arguably more extreme than those we have chosen to recount which suggest that the activities we highlight are by no means rare in academia. For this reason, we feel it is important to bring these stories to light: they tell us something important about the 'secret life' of academia.

\section{Vignette 1: The big red cloud}

Jim works in a UK business school. We spoke to him about the changes he feels obliged to make to his work during the review process. Even though he feels that such changes are sometimes unnecessary and gratuitous, he justifies his approach by comparing academic knowledge production to artistic labour:

Imagine you're an artist and you paint a picture and someone says, 'Wouldn't it be better if you had a big red cloud over in that corner?' And you're thinking, 'No, actually I like the picture as it is'. But you know no one is going to buy the picture unless you put the red cloud in the corner. So you do have to dance to tunes.

Of course, reviewer comments and editorial suggestions often help an author to improve their paper in various ways. But what is interesting here is the 
metaphor of the 'big red cloud' that Jim uses to talk about his experiences of the review process. Just as artists come under pressure to change the nature of their work to satisfy consumer demands, so scholars may feel compelled to modify the nature of their research to 'sell' it to academic joumals. The type of change is significant here: it is not a minor innocuous detail that is added, but a substantial and incongruous one (the cloud is not only big but also red). Crucially, Jim is motivated to put metaphorical red clouds in his work not primarily to strengthen the paper but rather to appease reviewers and editors - that is, he feels obliged to 'dance to tunes'. Although Jim says that his work is usually improved as a result, he also becomes distanced from his own research:

Sometimes you put the red cloud in the comer and you think, 'Actually, that does balance the picture off well, the colours do work, aesthetically it's great, and I can see why it works for other people in that way'. And overall, if you ask 100 people about my original painting, probably 90 would prefer the one with the red cloud. It's just that it's not the picture that I intended to draw or to paint. [...] It adds to the paper and it makes the paper more accessible or more interesting or work better or whatever, but it's taken me away from where I wanted to go. It's not that the paper that's published is inferior, it's just different, it's no longer my baby.

Many scholars may recognize this description of what happens to one's research as it gets squeezed through the review process, bending it out of its original shape. Notwithstanding the fact that one may consider the published version an improvement over the initial submission, this process of distancing raises important questions about how scholars come to relate to their own research. As we shall see in the following vignette, the regime of excellence provides scholars with an alibi to modify the content of their work in line with the demands of elite journals in significant (and not always desirable) ways.

\section{Vignette 2: Cats and dogs}

William works in a US university. He told us about a paper he is particularly proud of that is published in a top-ranked journal. Despite the 'homogenizing nature' of the review process, he considers his paper to be 'subversive' although, he admitted, not as subversive as it could have been had he published it elsewhere. Interestingly, he told us that he would not have considered withdrawing this particular paper from review even if he had been asked by the reviewers to make compromises to his core argument. As he put it, 'I think that if they had told us, "Turn it into a paper about cats and dogs", we might have been willing to do that. And that's very bad. That's clearly very bad'. What intrigues us here is the fact that William would be willing to make thoroughgoing changes to his work for the sake of publication even though he fully accepts this would contravene his own research ethos. We probed him further on this point: 


\section{Nick Butler and Sverre Spoelstra}

Interviewer: Why would you have been willing to make that sacrifice?

William: I think it's a subversive paper.

Interviewer: But not if it's going to be about cats and dogs in the end, right?

William: Well that depends. Which cats and which dogs?

Interviewer: You would only write about subversive cats and dogs? [Laughs]

William: No, I don't know. It's a great question. How far would we have had to push it before we would have said this is no longer [acceptable]. Partly it's that at that specific moment in time - and this gets at the pressures of the profession - my co-author needed this.

When nudged a little to explain why he would - in metaphorical terms - turn his paper into one about cats and dogs if so requested by a premier outlet, William offers a simple yet troubling explanation: 'my co-author needed this'. We do not doubt this is the case, but it is interesting to note how easily questions about the nature and purpose of scholarship come to be superseded by issues around career progression and promotion opportunities (even if they are altruistically motivated). On an individual level, this may have negligible effect on the quality of research in the field as a whole. But, as we shall see in the next vignette, such external motivations serve to shape research practices and knowledge production in more alarming ways once they are viewed in broader institutional terms.

\section{Vignette 3: The logical conclusion}

Paul, who works in a UK business school, told us about an extreme example of academic game-playing that takes place elsewhere in Europe:

I know of a European business school that pays six thousand Euros if you make one of their employees a co-author on your paper. They have a list which roughly equates to 3 - and 4-star journals on the ABS list. [...] It's all via word of mouth, but it's not exactly a secret either. I learnt about it because an ex-colleague of mine works there now. He explained the mechanics to me quite in detail and gently invited me to play along.

In one sense it is shocking that a business school would be willing to pay scholars from other universities to include its employees on the byline of papers they have not written. But while the idea of 'cash for co-authorship' may strike us as antithetical to the professional integrity of academic work, for Paul it is quite explicable within the logic of excellence. Indeed, he views such practices as an extension of the types of game-playing that are already part and parcel of contemporary academic life:

[The European business school does this] because otherwise they would lose their accreditation a few years down the line. And I don't blame them 
for doing it. I mean, if you play the game, you may as well play straight down the line. Departments who hire professors just before an RAE or REF deadline do exactly the same, only they spend more money and may be stuck with a colleague they don't really want. And then there are so many academics in the business of exchanging co-authorships of course: 'I'll put you on my paper if you put me on your paper'. There is no fundamental difference really. In a way I find it comforting in an absurd kind of way to know that people are taking the game to its logical conclusion. If papers, and more importantly authorship of papers, become totally commodified then it makes sense to actually put an explicit price on it.

For Paul, the outright commission of academic articles is not substantively different from other forms of gamesmanship in higher education; hiring REF-able professors shortly before research assessments or establishing mutually beneficial quid pro quo publication partnerships just happen to be more institutionally acceptable in the current climate. We probed further and asked Paul whether he would ever consider commodifying his own co-authorship and selling it to this business school. He told us:

I would have absolutely had no qualms whatsoever [...] I had the process well under way. The only snag was that at the last minute our paper was rejected after a second [revise and resubmit]. One-nil to the system I guess. I had actually already worked out how to spend the money: book a chef's table for ten people at a top restaurant [...] and blow the whole $6 \mathrm{k}$ on a fantastic evening together. An aesthetic way of dealing with the madness of it all, as it were.

While this is a limit case of academic game-playing, it nonetheless epitomizes the kind of dilemmas that many academics face in a professional sphere that values the mere fact of publication in certain outlets over and above other modes of scholarly engagement. Indeed, we see a common theme running through all three vignettes, from making unnecessary changes to one's work during the review process to increase the chances of publication, to compromising one's core research contribution for the sake of enhancing the career prospects of oneself or one's colleagues, to agreeing to write an academic article for another scholar in exchange for cold hard cash. Taken together, they point towards the way that academics willingly accede to the 'rules of the game' and, in so doing, reconfigure the conditions of knowledge production in the business school in new and troubling ways. Put bluntly, academic research is becoming increasingly geared around external considerations such as journals rankings, job prospects and explicit financial incentives. This marks a worrying shift away from the core questions that have historically guided scholarship - namely, what is my research about and why does it matter? 


\section{Nick Butler and Sverre Spoelstra}

\section{Vignette 4: Meet the editor}

One often hears it said that, for all its faults, the regime of excellence ultimately serves to produce high quality research in the best journals in the field. This argument is often made with reference to the thorough processes of screening and selection in the top tier outlets, most clearly evinced - so we are told - by astronomically high rates of rejection. But this familiar narrative, as we will see in our final vignette, does not always stand up to closer scrutiny.

Gary, who is based in the UK, talked to us about his role as associate editor for a top-ranked European journal:

Gary: A journal like the one which I edit, it's almost a disposal operation. So basically what we spend most of our time doing is disposing of 95 per cent of the work which people do, right? Which is kind of weird.

Interviewer: Are you then happy about the 5 per cent that does get through?

Gary: No. [...] The first year I was involved in the joumal, we had to go through and basically work out which was the best article of the year. I remember looking through, I don't know, 10 articles with my fellow editors. I went through and looked [and] all of them were not just boring but were so deadly depressing, I felt that it was impossible basically. I just couldn't do it, you know. It just made me really, really depressed about the whole enterprise essentially.

It is remarkable that we have arrived at a situation where even senior editors are bored and depressed by the 'best' work published in their own journal. And this is not an isolated case: two other senior editors we spoke to described much of the output in the highly rated joumal they edit as interminably dull. This tells us that something has gone very wrong in organization studies, particularly among elite outlets that dominate the field. We may wonder how we have reached a situation where a subjective criterion of excellence - based on trained judgement and professional discretion - can diverge so vastly from its 'objective' measure according to journal ranking systems.

But the more pressing question is how we might respond to all of this. In other words, is there another way of dealing with 'the madness of it all', as Paul so poignantly put it, other than simply allowing oneself to be swept along by the momentum of excellence? We now turn to this question in the remainder of the chapter.

\section{The sublime object of excellence}

In the Sublime Object of Ideology, Žižek (2008) highlights the nature of contemporary ideology. Illustrating his argument with reference to Marx, Žižek notes that ideology today works in the same way as commodity fetishism. Take money, for instance: we all know that the object of monetary exchange (a coin 
or note) is concrete and perishable, getting scratched or crumpled in our pockets, but we act as if money were an unchangeable and universal substance. It is not the case that individuals really believe that money is magical; they are under no illusion about the socially constructed nature of wealth. What is misrecognized, however, is the fact that the activity in question - in this case the act of exchange - is itself subject to fetishistic illusion, not the set of beliefs about the act. Žižek thus inverts the classic Marxist formula of ideology: it is no longer the case that individuals 'do not know what they do, but they are doing it' but, more worryingly, 'they know very well how things really are, but still they are doing it as if they did not know' (2008: 30).

Can we not view excellence as a 'sublime object' in the same sense as money? After all, academics know that there is nothing particularly numinous about systems of journal ranking that guide knowledge production in academia; they realize only too well that the actual content of research contained within the pages of academic joumals bears little intrinsic relation to the quantitative expression of quality (e.g. 1-star, 2-star, 3-star, 4-star). But still, academics often act as if excellence were something more than a matrix of social relations, as if it were a transcendental category that exists in and of itself. For example, journal rankings provide a mechanism for scholars to become 'objectively excellent', despite their personal reservations about the relative merits of this or that piece of research (indeed, much of it may be considered to be 'boring' or even 'deadly depressing', as Gary admits). This points to the radical exteriority of belief in contemporary academia, underscoring the fact that ideology in the business school operates not only through knowing or thinking but also, more pervasively, through doing and acting. This becomes most apparent in the case of William, who would have been willing to compromise the core argument of his paper - namely, turn it into one about cats and dogs if so requested by reviewers - even though he recognizes that this is "clearly very bad'.

Some scholars have proposed potential strategies to subvert such cynical ideology. Fleming and Spicer (2003: 172), for example, suggest that since cynical dis-identification serves to consolidate rather than challenge forms of social and cultural domination, the act of 'believing too much' in the prevailing ideology may have the converse effect of destabilizing it. We can see such ironic over-identification with excellence at work in the spoof Journal of Universal Rejection (www.universalrejection.org). As stated on its website, 'all submissions, regardless of quality, will be rejected'. This means, of course, that every author who submits a manuscript for consideration can 'claim to have submitted to the most prestigious journal (judged by acceptance rate)'. The disruptive logic here is precisely that of 'believing too much' in the efficacy of quantitative measures of assessment such as impact factors and journal rankings; it undermines these standard markers of quality precisely by extending their logic to the point of collapse, revealing the inherent absurdity of using formal metrics to determine the value of research. But we might also see this mode of dissent as ineffectual or even counter-productive. 


\section{Nick Butler and Sverre Spoelstra}

As we saw in vignette 3, taking excellence to its 'logical conclusion' may involve commodifying academic knowledge even further by putting 'an explicit price on it' (for example, accepting cash for co-authorship). The danger, of course, is that such ironic over-identification may be, for all intents and purposes, indistinguishable from academic game-playing; from this perspective, there really is 'no fundamental difference', as Paul suggests, between hiring REF-ready professors and commissioning academic articles for the sake of research assessment exercises.

\section{You must change your life}

What is needed are fewer gestures of ironic over-identification and more attempts to reflect seriously on how our research practices have changed over time as a result of excellence - and what we might do about it. Many of the professors we interviewed spoke explicitly about playing the publication game. We find this disturbing but also reassuring. Disturbing, because it shows how easy it is for management researchers to reorient the goal of scholarship around other, extemal - often instrumental - motivations; reassuring, because becoming aware of oneself as a player of the game may be the first step towards counteracting some of the worst excesses of excellence. This is what Sloterdijk (2013: 145) points to in You Must Change Your Life:

[I] the players are themselves inescapably affected by what they play and how they play it (and how it has been drilled into them to play it), they will only have access to the bridge of their self-change by recognizing the games in which they are entangled for what they are.

If we wish to enact the 'self-change' that Sloterdijk speaks of, it is not enough simply to recognize the game itself; it is also necessary to consider the different ways in which the game is played and how we might change our orientation towards it. This involves scrutinizing all those relatively minor choices we make at every stage of the research process from initial conception to eventual publication - in other words, to take seriously the 'tyranny of small decisions' (Kahn, 1966) that has such a significant effect on the nature of scholarship in the business school. This is a much more difficult task to undertake since it compels us to acknowledge that the regime of excellence is not simply a force majeure that is imposed upon us from the outside, but also a set of relations we voluntarily maintain with ourselves and others.

This presents us with an opportunity to reflect on how we write, research and publish within the university-based business school. In an earlier paper, we suggested that academics should develop an ethos of research that is not in thrall to the regime of excellence; this, we said, will require us to adopt an 'uncomfortable honesty' towards ourselves as scholars (Butler \& Spoelstra 2014). Social psychologist Michael Billig (2013) provides a striking example of such uncomfortable honesty in his book Learn to Write Badly: How to Succeed in 
the Social Sciences. Admonishing himself for being overly concerned with the citation count for his own academic publications, he reflects on his own 'vanity and insecurity':

It doesn't seem to matter how the others are mentioning me, whether they do so in passing or at length, whether in complimentary or critical tones. All that matters is that I am mentioned, again and again. It gets worse. Sometimes, I have compared my scores with those of others. I am pleased if I am mentioned in more articles than they are, and my mood will be spoiled if their numbers surpass mine...Do I really think like this? Do I really care about the numbers? I must do. What a knob head.

(2013: 155)

A few management scholars have reflected in a similar way on how their own research practices have become intertwined with less than noble motives for knowledge production. Ashforth (2005: 401), for example, acknowledges that he has been 'guilty of doing more than one study not because I believed the core ideas were so vital but because the studies were readily doable'. It is this 'doability' - or 'publishability' - that seems to drive much research in the business school, critical or otherwise. Similarly, a recent piece - published anonymously - reflects on the process of post-hoc hypothesizing for the sake of securing publication: 'I never fudged data, but it did seem like I was fudging the framing of the work, by playing a little fast and loose with the rules of the game' (Anonymous, 2015: 215). It is worth noting that this author engaged in such activities in part because it allowed 'my junior colleague [to] achieve a much needed "A" publication' (2015: 215), which directly echoes William's motivations in vignette 2 . Such moments of candour, however, are few and far between in management and organization studies.

In her provocative 'non-survival guide' to higher education, Bristow (2012: 238) calls upon critical scholars to act out their 'inner John the Savage' - Huxley's figure of social marginality and political refusal in Brave New World - by raising 'inappropriate' or 'indecent' questions about the value of research assessments and journal rankings at performance appraisals, department meetings or pep-talks by the Vice-Chancellor (2012: 238). But what if the inappropriate and indecent questions were not directed at others, but at oneself? Consider the following:

- How far has my research been shaped by a view to 'publishability' over and above more scholarly concerns (e.g. interest, importance, relevance)?

- To what extent have I collaborated with senior researchers to piggyback on their reputation and guarantee a smoother ride through the publication process?

- To what extent have I collaborated with junior researchers to gain access to their data sets and artificially inflate my own outputs?

- How far has my data been salami-sliced into the 'least publishable unit'? 
86 Nick Butler and Sverre Spoelstra

- What would it take for me to withdraw a paper from the review process rather than accede to requests for revision that I deem to be unnecessary, unhelpful or unreasonable?

- Finally, am I submitting my work to an outlet that I consider to be worthy of my support?

While these questions are partly tongue-in-cheek, they point towards a potential ethos of non-excellence in academia. Such an ethos would not stop at merely raising these questions for oneself, remaining at the level of belief, but would instead seek to put them into practice. To return to our vignettes, we would be in a situation where researchers would hesitate when asked, in metaphorical terms, to paint a 'big red cloud' into their paper. Ultimately, becoming 'less excellent' would serve to emphasize research quality over journal rankings, academic debate over impact factors, and critique over careerism - thereby allowing management scholars to 'publish without betrayal' (Özkazanç-Pan 2012).

\section{Conclusion}

We would like to end with a final vignette drawn from our own experience. A few years ago, one of the authors of this chapter attended a research meeting at his home university (which, we should note, is not an institution where the regime of excellence rules with an iron fist). At the end of the meeting, a senior professor encouraged everyone to share their research 'breakthroughs' with the group. One researcher announced that he had recently had a paper accepted for publication in an ABS 4-rated journal. This news was received with a round of applause and heartfelt congratulations. As the hubbub died down, another researcher announced that she had also had a paper accepted for publication in a journal that is ABS 2-rated. This time, there was an awkward silence in the room, which on this occasion spoke louder than words, as if to say, 'Ok, but that's not a good journal...'

This brief anecdote tells us something crucial about where we are in academia today - namely, the fact that the outlet in which academic research appears is valued more than the content of the work itself. Indeed, the substance of an argument or the nature of ideas seem to take second place to the relative prestige of the journal in question (understood solely in terms of journal ranking), even in the context of an informal research meeting among colleagues. The applause for a four-star publication and the silence for a two-star publication speaks volumes about the way in which academics are now willing to outsource the evaluation of research to extemal measures of quality. In so doing, the logic of excellence is reinforced not only through research assessment exercises that we are obliged to undertake, but also - more pervasively - through our everyday activities that are wholly voluntary. This suggests, as others have pointed out, that there is an ongoing 'perversion of scholarship' (Willmott 2011) as a result of the increasing prominence of journal rankings and other performance indicators in the contemporary business school. 
One response to this, of course, is to play the game at the same time as maintain a cynical distance towards it - this is a position adopted by many critical scholars that we spoke to. An alternative response, however, would be to call excellence to account whenever and wherever we encounter it, both in our own practices and those of others. This might be done with a degree of humour, pointing out the absurdities of excellence. For example, we might envisage a future world where we would congratulate journals for accepting high-quality scholarship for publication (rather than automatically applauding individuals who publish in top-tier outlets). Or again, we might begin to view the 'trickle-down theory of journal publishing' (i.e. submit your papers to topranked journals first and then, if they are rejected, work your way down to lower rated outlets) with the same scepticism as its neoliberal counterpart, the trickle-down theory of economics (i.e. a rising tide lifts all boats). Our proposals here are broadly in line with Pritchard's (2013) suggestion that we need to find ways to stimulate 'excellentricity' - a neologism that combines 'excellence' and 'eccentricity' - in the business school. This calls upon us to become decentred, or ex-centric, in our approach to journal publishing, signalling a move away from the ambiguous domain of ironic over-identification (believing too much in excellence) and towards a more subversive position on the margins (doing as little as possible for excellence). There is an acknowledgement here that we cannot remove oneself from the game entirely; there is no outside to excellence, at least not within the university as it is presently constituted (Rolfe 2013). What we can do, however, is remain vigilant against the most pernicious effects of excellence in academia and attentive to the potential tyranny of small decisions in our own research practices, which - in Sloterdijk's words - would be the first step to accessing the bridge of our self-change.

\section{Epilogue}

Since we began this research project in 2011, both authors have become considerably more 'excellent'. Ironically, this has been due in part to publishing papers in highly ranked journals on academic game-playing (Butler \& Spoelstra 2012; 2014). We are no longer writing from the margins, but from a relatively established position within ongoing discussions in organization studies on journal rankings and research assessments. Part of the reason why this chapter has been so uncomfortable to write - and why it demands heightened levels of honesty, especially towards ourselves - has been precisely this shift in our professional status. Readers would therefore be justified in asking: why are we still banging on about academic game-playing instead of simply withdrawing from the game itself? Have we become so absorbed into the game that we no longer recognize ourselves as academics at play? These are crucial issues to confront oneself with.

A few final comments are therefore required to reflect on our own journey towards publication. This chapter began life as a paper written for a relatively lowly ranked joumal (ABS 2-rated), but it was rejected because it was deemed 


\section{Nick Butler and Sverre Spoelstra}

to be, in the words of the editor, 'more of an essay than a research paper'. We subsequently revised and resubmitted it to a higher ranked journal (ABS 3-rated). During the review process, we expanded our theoretical framing, developed our method section and extended our discussion. The result was a paper that, in our estimation, could be seen as a contribution to critical management studies. And this was precisely the problem: we had transformed our provocative think-piece into a typical journal article. This had partly to do with reviewers' comments and editorial suggestions, but also with our own projections about what a journal article is 'supposed to' look like.

One of the questions we encourage authors to ask themselves was therefore unavoidable in our case, namely, what would it take for us to withdraw our paper from the review process? Of course, we told ourselves that the requests for revisions were necessary, helpful and reasonable, even if we privately sneered at some of the suggestions (expanding the method section, for example). We felt that we were always 'in with a chance' of publication, and this - we have to admit - provided a considerable motivation to revise the paper, even (or especially) when we stopped enjoying the process of writing and rewriting. Periodically, one author would lose interest in the paper while the other would plough on regardless; it became at some point almost mechanical. We both became painfully aware of the way our initial drive for the paper slowly became reoriented around a different set of goals that had arguably less to do with scholarship and more to do with strategizing (e.g. does our literature tick the right boxes? Is our method section convincing enough?), not least due to the 'sunk costs' involved in crafting a submission for publication over a period of time.

Nonetheless, after some agonizing, we eventually decided to withdraw our paper from the review process and instead to publish it as ichapter in this edited collection - a publication, we note, that is outside the purview of excellence. We withdrew our paper because we felt uncomfortable that it had started to resemble our previous journal articles on the topic of 'excellence' (Butler \& Spoelstra 2012; 2014). On the one hand, this may seem to be a noble and selfless act: refusing to compromise and making sacrifices in order to maintain our academic integrity. On the other hand, we can cast doubt on this narrative. After all, there was no guarantee that our paper would have been accepted for publication in the journal (we faced another round of major revisions). Would we have withdrawn our paper if the required changes were 'minor'? Most likely not, we must admit. Furthermore, the present chapter closely resembles the paper we withdrew from the review process. Maybe we just could not face doing any more work on the paper and took the easy way out: an invited book chapter with a light-touch peer review.

\section{Note}

1 This chapter has its origins in a Professional Development Workshop entitled 'How to become less excellent', facilitated by the authors and held at the 73rd Annual Meeting of the Academy of Management (9-13 August 2013), Orlando, FL, United States. 


\section{References}

Adler, N.J. and Harzing, A.W. (2009) 'When Knowledge Wins: Transcending the Sense and Nonsense of Academic Rankings', Academy of Management Learning $\mathcal{E}$ Education 8(1): 72-95.

Alvesson, M. and Sandberg, J. (2013) 'Has Management Studies Lost its Way? Ideas for More Imaginative and Innovative Research', Joumal of Management Studies 50(1): 128-152.

Anonymous (2015) 'The Case of the Hypothesis That Never Was: Uncovering the Deceptive Use of Post Hoc Hypothesis', Joumal of Management Inquiry 24(2): 214-216.

Ashforth, B.E. (2005) 'Becoming Vanilla Pudding: How We Undermine Our Passion for Research', Journal of Management Inquiry 14(4): 400-403.

Billig, M. (2013) Learn to Write Badly: How to Succeed in the Social Sciences. Cambridge: Cambridge University Press.

Bristow, A. (2012) 'On Life, Death and Radical Critique: A Non-Survival Guide to the Brave New Higher Education for the Intellectually Pregnant', Scandinavian Journal of Management 28(3): 234-241.

Butler, N. and Spoelstra, S. (2012) 'Your Excellency', Organization 19(6): 891-903.

Butler, N. and Spoelstra, S. (2014) 'The Regime of Excellence and the Erosion of Ethos in Critical Management Studies', British Journal of Management 25(3): 538-550.

Cederström, C. and Hoedemaekers, C. (2012) 'On Dead Dogs and Unwritten Jokes: Life in the University Today', Scandinavian Journal of Management 28(3): 229-233.

Clarke, C., Knights, D. and Jarvis, C. (2012) 'It's a Bittersweet Symphony, This Life: Fragile Academic Selves and Insecure Identities at Work', Organization Studies 35(3): 335-357.

Craig, R., Amemic, J. and Tourish, D. (2014) 'Perverse Audit Culture and Accountability of the Modem Public University', Financial Accountability \& Management 30(1): 1-24.

Davis, G.F. (2014) 'Why Do We Still Have Joumals?' Administrative Science Quarterly 59 (2): 193-201.

Deem, R., Hillyard, S. and Reed, M. (2007) Knowledge, Higher Education, and the New Managerialism: The Changing Management of UK Universities. Oxford: Oxford University Press.

Fleck, C. (2013) 'The Impact Factor Fetishism', European Joumal of Sociology 54(2): 327-356.

Fleming, P. and Spicer, A. (2003) 'Working at Cynical Distance: Implications for Power, Resistance and Subjectivity', Organization 10(1): 157-179.

Higher Education Statistics Agency (2014) 'Statistical First Release 209 - Staff at HE Providers in the UK'. https://www.hesa.ac.uk/news/18-12-2014/sfr209-staff]. Accessed 1 December.

Hussain, S. (2011) 'Food for Thought on the ABS Academic Journal Quality Guide', Accounting Education 20(6): 545-559.

Hussain, S. (2015) 'Journal List Fetishism and the "Sign of 4" in the ABS guide: A Question of Trust?', Organization 22(1): 119-138.

Kahn, A. (1966) 'The Tyranny of Small Decisions: Market Failures, Imperfections, and the Limits of Economics', Kyklos 19(1): 23-47.

Knights, D. and Clarke, C.A. (2014) 'It's a Bittersweet Symphony, This Life: Fragile Academic Selves and Insecure Identities at Work', Organization Studies 35(3): 335-357.

Lucas, L. (2006) The Research Game in Academic Life. Maidenhead: Open University Press.

Macdonald, S. (2014) 'Emperor's New Clothes: The Reinvention of Peer Review as Myth', Joumal of Management Inquiry 24(3): 264-279. 


\section{Nick Butler and Sverre Spoelstra}

Macdonald, S. and Kam, J. (2007) 'Ring a Ring o' Roses: Quality Journals and Gamesmanship in Management Studies', Joumal of Management Studies 44(4): 640-655.

Macdonald, S. and Kam, J. (2011) 'The Skewed Few: People and Papers of Quality in Management Studies', Organization 18(4): 467-475.

Malsch, B. and Tessier, S. (2015) 'Journal Ranking Effects on Junior Academics: Identity Fragmentation and Politicization', Critical Perspectives on Accounting 26: 84-98.

Martin, B.R. (2013) 'Whither Research Integrity? Plagiarism, Self-Plagiarism and Coercive Citation in an Age of Research Assessment', Research Policy 42(5): 1005-1014.

McDaniel, T.R. and Childers, P.B. (2011) 'Winning at the Publication Game', The Clearing House: A Journal of Educational Strategies, Issues and Ideas 84(5): 171-173.

Mingers, J. and Willmott, H. (2013) 'Taylorizing Business School Research: On the "One Best Way" Performative Effects of Joumal Ranking Lists', Human Relations 66(8): 1051-1073.

Nkomo, S.M. (2009) 'The Seductive Power of Academic Journal Rankings: Challenges of Searching for the Otherwise', Academy of Management Learning \& Education 8(1): 106-121.

Northcott, D. and Linacre, S. (2010) 'Producing Spaces for Academic Discourse: The Impact of Research Assessment Exercises and Journal Quality Rankings', Australian Accounting Review 20(1): 38-54.

Özkazanç-Pan, B. (2012) 'Publishing Without Betrayal: Critical Scholarship Meets Mainstream Journals', Scandinavian Joumal of Management 28(3): 209-217.

Prasad, A. (2013) 'Playing the Game and Trying Not to Lose Myself: A Doctoral Student's Perspective on the Institutional Pressures for Research Output', Organization 20(6): 936-948.

Pritchard, C. (2013) 'Ten Steps Towards Excellentristic Research', paper presented at the 73rd Annual Meeting of the Academy of Management, 9-13 August, Orlando, FL, United States.

Readings, B. (1996) The University in Ruins. Cambridge and London: Harvard University Press.

Retraction Watch(2014) 'Overly Honest References: "Should we cite the crappy Gabor paper here?”, 11 November.http://retractionwatch.com/2014/11/11/overly-honest-ref erences-should-we-cite-the-crappy-gabor-paper-here.

Rolfe, G. (2013) University in Dissent: Scholarship in the Corporate University. London: Routledge.

Rowlinson, M., Harvey, C., Kelly, A. and Morris, H. (2011) 'The Use and Abuse of Journal Quality Lists', Organization 18(4): 443-446.

RowlinsonM., Harvey, C., Kelly, A., Morris, H. (2015) 'Accounting for Research Quality: Research Audits and the Journal Rankings Debate', Critical Perspectives on Accounting 26: 2-22.

Shore, C. and Wright, S. (1999) 'Audit Culture and Anthropology: Neo-liberalism in British Higher Education', Journal of the Royal Anthropological Institute, 5(4): 557-575.

Sloterdijk, P. (2013). You Must Change Your Life, trans. W. Hoban. Cambridge and Malden: Polity.

Tienari, J. (2012) 'Critical Scholars in the Machinery of Publishing: Experiences, Reflections, Alternatives', Scandinavian Journal of Management 28(3): 205-208.

Tourish, D. (2010) 'Publish or Be Damned', Times Higher Education, 16 December.

Tourish, D. and Willmott, H. (2015) 'In Defiance of Folly: Joumal Rankings, Mindless Measures and the ABS Guide', Critical Perspectives on Accounting 26: 37-46. 